\title{
INEQUALITIES FOR THE RATIOS OF CERTAIN BIVARIATE MEANS
}

\author{
EDWARD NEUMAN AND JÓZSEF SÁNDOR
}

Abstract. Inequalities connecting ratios of bivariate homogeneous means whose variables satisfy certain monotonicity conditions are obtained. Derived results include the Stolarsky, Gini, Schwab-Borchardt, and lemniscatic means.

Mathematics subject classification (2000): 26D05, 33E05.

Key words and phrases: Stolarsky means, Gini means, Schwab-Borchardt mean, lemniscatic mean, inequalities.

\section{REFERENCES}

[1] J. M. Borwein And P. B. Borwein, Pi and the AGM - A Study in Analytic Number Theory and Computational Complexity, Wiley, New York, (1987).

[2] B. C. CARlson, Algorithms involving arithmetic and geometric means, Amer. Math. Monthly, 78 (1971), 265-280.

[3] B. C. CARlson, The logarithmic mean, Amer. Math. Monthly 79 (1972), 615-618.

[4] P. CZINDER AND Zs. PÁLES, An extension of the Hermite - Hadamard inequality and application for Gini and Stolarsky means, J. Inequal. Pure Appl. Math., 5(2) (2004), Article 42 (electronic) URL: http: / / jipam.vu.edu/au/images/167_03_JIPAM/167_03.pdf.

[5] C. GINI, Di una formula comprensiva delle medie, Metron 13 (1938), 3-22.

[6] K. GuAN AND H. ZHoun, The generalized Heronian mean and its inequalities, Univ. Beograd, Publ. Elektrotehn. Fak., Ser. Mat., 17 (2006), 60-75.

[7] W. Janous, A note on generalized Heronian means, Math. Inequal. Appl., 3 (2001), 369-375.

[8] E. B. LeACH AND M. C. Sholander, Extended mean values, Amer. Math. Monthly, 85(2) (1978), 84-90.

[9] E. Neuman, On Gauss lemniscate functions and lemniscatic mean, Math. Pannonica, 18(1) (2007), 77-94.

[10] E. Neuman And Zs. PÁLes, On comparison of Stolarsky and Gini means, J. Math. Anal. Appl., 278 (2003), 274-284.

[11] E. NEUMAn AND J. SÁNDOR, Inequalities involving Stolarsky and Gini means, Math. Pannonica, 14(1) (2003), 29-44.

[12] E. Neuman And J. SÁndor, On the Schwab-Borchardt mean, Math. Pannonica, 14(2) (2003), $253-266$.

[13] E. NEUMAN AND J. SÁNDOR, On the Ky Fan inequality and related inequalities II, Bull. Austral. Math. Soc., 72 (2005), 87-107.

[14] E. NEUMAN AND J. SÁndor, On the Schwab-Borchardt mean II, Math. Pannonica 17(1) (2006), 49-59.

[15] ZS. PÁLES, Inequalities for differences of powers, J. Math. Anal. Appl., 131 (1988), 271-281.

[16] I. PINELIS, On L'Hospital-type rules for monotonicity, J. Inequal. Pure Appl. Math., 7(2) (2006), Article 40 (electronic) URL: http: / / jipam.vu.edu.au/images/157_05_JIPAM/157_05.pdf.

[17] J. SÁNDOR, Monotonicity and convexity properties of means, Octogon Math. Mag., 7(2) (1999), $22-27$.

[18] K. B. Stolarsky, Generalization of the logarithmic mean, Math. Mag., 48(2) (1975), 87-92.

[19] H.-J. SEIFFERT, Problem 887, Nieuw. Arch. Wisk., 11 (1993), 176.

[20] H.-J. SeIfFERT, Augabe 16, Wurzel, 29 (1995), 87.

[21] M. K. VAmanamurthy And M. Vuorinen, Inequalities for means, J. Math. Anal. Appl., 183 (1994), 155-166. 